\title{
Exploring Mouse Trap History
}

\author{
Joachim L. Dagg
}

Published online: 8 February 2011

(C) Springer Science+Business Media, LLC 2011

\begin{abstract}
Since intelligent design (ID) advocates claimed the ubiquitous mouse trap as an example of systems that cannot have evolved, mouse trap history is doubly relevant to studying material culture. On the one hand, debunking ID claims about mouse traps and, by implication, also about other irreducibly complex systems has a high educational value. On the other hand, a case study of mouse trap history may contribute insights to the academic discussion about material culture evolution. Michael Behe argued that mouse traps cannot trap mice with any part missing; therefore, they cannot have a precursor with one part less, therefore, cannot have a continuous history, and therefore, cannot have evolved. The patented and seminal precursor of current flat snap traps, however, had one part less, because spring and striker were formed of one wire. Secondly, historical records that reach back into the Bronze Age suggest that its history continued for a very long time. Thirdly, all prerequisites for evolution (variation, transmission, and selection) abound in mouse trap populations. Hence, Behe's triple-jump conclusion about mouse traps is false each step. There is no, in principle, impossibility for mouse traps to evolve. An evolutionary account of mouse trap history also has academic merits beyond its educational value. Three important conclusions can be drawn: (1) reticulate phylogenies of artifact systems may be resolvable as overlapping, but branching, phylogenies of parts; (2) homologous ideas may be realized by analogous material, that is, phylogenies of information do not necessarily coincide with those of material parts; (3) recombination of parts between different artifact systems increases the cumulative nature of cultural evolution.
\end{abstract}

J. L. Dagg $(\bowtie)$

Heinrich-Böll-Schule, Schulstr. 100,

65795 Hattersheim, Germany

e-mail: jdagg@gmx.de
Keywords Irreducible complexity · Lateral transfer . Hannah principle

\section{Introduction}

Mouse trap history is not (yet) an established subject of research in the history of material culture. This ignorance allowed Michael Behe (1996) to claim the ubiquitous flat snap trap as an example for a system that ostensibly cannot have evolved. These traps cannot catch mice with any one part missing. From this simple fact, called irreducible complexity, Behe drew a triple-jump conclusion: (1) irreducibly complex systems can have no working precursor with one part less; (2) therefore, they can have no continuous history; (3) therefore, they cannot evolve.

This anti-Darwinian challenge makes a closer look at mouse trap history particularly pertinent to the study of material culture. Part I (Refuting Behe's Triple-Jump Conclusions) of this contribution proves Behe's conclusions wrong each step: (1) The seminal precursor of current flat snap traps had one part less. (2) Mouse trap history is continuous and very old. (3) All prerequisites for evolution occur in mouse trap populations.

Part II (Material Culture Evolution) lays the groundwork for a case study in material culture change. This discussion is currently in full swing concerning evolutionary archeology (e.g., O'Brien and Lyman 2004; Gabora 2006). Here, mouse traps can cover the middle ground between artifacts that are made of only one part (e.g., stone tools) and highly sophisticated machines with a large number of parts (e.g., steam engines, cars, and computers), and they can bridge the time from the Bronze Age to the present.

In the end, part I illustrates why each of Behe's conclusions is false and part II, why the pros and cons of 
material culture evolution can, nevertheless, be freely discussed without feeling pressed to either side by creationist claims. At the outset, however, a conceptual framework is needed.

\section{Conceptual Framework}

Artifact production is analogous to development (ontogeny), and artifact history is analogous to natural history (evolution). Dissimilarities concern variation, transmission, and selection.

\section{Variation}

Cultural variation is neither blind (mutation) nor clairvoyant. Producers do not reproduce artifacts faithfully or vary them blindly. Cultural transmission is not exact copying but imitation in combination with human goals. This individual "teleology" assures that variants are functional. Boyd and Richerson (1985) refer to this as guided variation. A functional variant may nevertheless fail to be transmitted because human designers lack clairvoyance (Mesoudi et al. 2004; Nelson 2007; Mesoudi 2008).

\section{Transmission}

Cavalli-Sforza and Feldman (1981) distinguish vertical from oblique and horizontal transmission of cultural traits. Vertical transmission takes place between related individuals (e.g., parent-offspring). It runs in parallel to germ-line transmission. Horizontal transmission takes place between non-related individuals of the same generation (e.g., classmates). Oblique transmission takes place between unrelated individuals of different generations (e.g., teacher-student).

In reconstructing artifact history, however, it is necessary to establish relations of artifacts rather than their producers. Therefore, slightly different concepts are used. Descending transfer takes place if an artifact is copied with minor variations but no parts are borrowed from other artifacts. For example, a cage trap is copied without replacing the set/ release mechanism by one from another trap kind, and so for all parts. Although this transfer descends along the lineage of cage traps, the producers in question need not be genetically related. Descending transfer only coincides with vertical transmission, if the producers happen to be related.

Likewise, the lateral transfer of parts between artifacts differs from horizontal transmission. Lateral transfer takes place if, for example, a set/release mechanism from a cage trap is introduced into a choker trap. Although this transfer crosses the boundary between artifact systems, which users perceive as different kinds, the inventors in question could be genetically related. An inventor could even recombine parts of different artifacts, which he both invented himself.
This would be lateral transfer of parts despite the inventor(s) being genetically identical.

Lateral transfer is neither blending. Blending inheritance means that the phenetic expressions of descendants are averages of the ancestors' and that no segregation can occur in later filial generations. Blending destroys variation (see Cavalli-Sforza and Feldman 1981). Assuming blending inheritance, Fleming Jenkin (1867) famously refuted Darwin's The Origin of Species, because "the sport will be swamped by numbers, and after a few generations its peculiarity will be obliterated."

The lateral transfer of parts between systems, however, creates new variants and does not preclude the separate transmission of once combined parts later on. It is therefore a form of recombination, though more like the uneven and irregular one found in prokaryotes rather than in sexual organisms (Wimsatt 1999). Recombination between technological systems is very important, almost the essence of invention. While it often takes place between similar artifacts (e.g., cage and choker traps), there is no limit to recombination between artifacts with different purposes.

\section{Selection}

Natural selection is an inevitable consequence of competition between individuals with heritable variation in fitness. Nothing actively does the selecting. Cultural selection, however, is due to values which can be held by producers, vendors, and users alike.

Richerson and Boyd (2005) distinguish biased transmission from selection. Transmission biases are due to the preferences of individuals and selection is due to the effect that adopting a cultural variant has on the chance of being imitated. Some values causing cultural selection via transmission biases are identified in the following. The question of how adopting a better mouse trap may have affected the survival (natural selection) of people is not addressed below.

\section{Homology, Cultural Transmission, and Common Sense}

It is more parsimonious to assume a common culture pool, from which inspiration can be drawn, rather than so many convergent flashes of genius, even if the inventors in question were not always conscious of their sources. Therefore, if the decision is between lateral transfer and convergence, lateral transfer will be default as long as further evidence for convergence is lacking. There are good reasons for this shift of the onus from proving homology to proving analogy in traps.

Unlike biological traits or software (see Sole, this issue), traps do not contain a fine structure or code that can decide about homology. Microscopic differences of the vertebrate 
and octopus eye or different computer codes used for similar software performance prove convergence. Conversely, the wire parts of two different traps are not homologous just because their atomic structure is identical. Two traps are neither convergent just because they are made of different materials.

Inventors are free in their choice of materials. Thus, many mouse traps from the second half of the twentieth century rehash older designs using modern materials like cardboard, rubber band, plastics, or especially durable alloys of steel (Drummond 2009a). One should not, therefore, conclude that the inventors have each arrived at the mechanisms of their modern traps independently of the older designs. Twisted fibers were replaced by wire springs or rubber bands and wooden parts by metal parts and plastics. An analogous nature of parts does not reveal whether the ideas were also analogous or homologous. The phylogenies of matter and information can differ.

Deciding about homology, here, becomes as difficult as the job of a patent officer. The patent officer's solution to this problem is to put the onus on the inventor to prove the novelty of his design, which is often a novel recombination of old parts. This solution agrees with common sense. No inventor ever claims to have an old idea shared with many antecedents, and nobody ever asks him to prove that. It is taken for granted that most ideas are old and shared. Likewise, I assume a common technology pool, from which inventors can freely draw inspiration, unless evidence for convergence exists.

Even the distinction between homologies as either shared ancestral or shared derived traits can become problematic, when artifacts linger on as antique pieces long after they ceased to be used. The problem is that an artifact gone extinct from the pool of actually used items may nevertheless be preserved and inspire recent inventors.

\section{Switching Perspectives}

Parts of artifacts are separately transmitted culture elements (Lagercrantz 1964; O'Brien et al. 2010). While users select whole systems based on their function, inventors recombine parts regardless of the systems they come from as long as that seems to yield an improvement. We can either adopt the perspective of physical parts and trace their lineage through different systems or we trace the lineage of a certain system and record the sudden appearance of new parts due to lateral transfer.

The part's eye-view may be as enlightening to the issue of material culture evolution as the gene's eye-view was to biological evolution, because it could show how a useful new part (e.g., a wire spring) spread into all sorts of technical systems. Moreover, it could reveal where a reticulate phylogeny contains overlapping, but branching, phylogenies of parts and where true blending occurs. The following review of historical trap records adopts the perspective on functional systems (traps), whereas a cladistic analysis of the wire spring is proposed from the part's eye-view.

\section{Fixing Terms}

Terms need to distinguish functions irrespective of the historical parts carrying them. It is useless to speak of a metallic platform, for example, if the part carrying that function was not metallic or not a platform in precursors. The general functions of the snap mouse trap in question are (1) striker, (2) set/release mechanism, (3) power source, and (4) base or framework to which these parts can be firmly attached.

\section{Part I: Refuting Behe's Triple-Jump Conclusions}

\section{Priority Issues}

William Chauncey Hooker (1894) patented a flat snap trap: "for catching mice and rats, a simple, inexpensive and efficient trap adapted not to excite the suspicion of an animal, and capable of being arranged close to a rat-hole." It allowed for mass production and went through many modifications (Drummond et al. 2002).

A safe-to-set modification of Hooker's design was invented by John Mast (filed 1899, patented 1903): "The object of the invention is to provide means whereby traps of this class [flat snap traps] may be readily set or adjusted with absolute safety to the person attending thereto, avoiding the liability of having his fingers caught or injured by the striker when it is prematurely or accidentally freed or released." The fact that Hooker sold his Animal Trap Company of Abingdon, IL, and it merged with the $J . M$. Mast Manufacturing Company of Lititz, PA, in 1905 (Drummond et al. 2002), may have contributed to a false attribution of priority to Mast (Hope 1996). Unfortunately, the misbelief in Mast's priority is transmitted (e.g., Shanks and Joplin 2000).

Others falsely credit priority to James Henry Atkinson of Leeds, UK (e.g., Bellis 2009). His "Little Nipper" received GB patent no. 27,488 in 1899 and has a treadle cut out of the whole width of the base. This increases the likelihood that the trap is sprung when a mouse only passes over it without being attracted to the bait. Another urban legend has Hiram Maxim, inventor of the machine gun, as inventor of the first flat snap mouse trap (e.g., "Mousetrap" by Wikipedia contributours, version before January 6, 2010). In his memoirs, however, Maxim (1915) described his inventions as automatic cage traps. The resetting automa- 
tism of one was powered by a coiled spring made from the hoop of a skirt, and that of the other was powered by the entering mice themselves.

\section{One Part Less: The Seminal Precursor}

The first mouse trap based on Hooker's patent was called "Out O' Sight" (Fig. 1) and produced in 1894 by the Animal Trap Company in Abingdon, IL.

This original design had the spring and striker formed of one wire. Current flat snap traps have separate spring and striker because their production and assembly is easier that way. This particular modification has not been patent-worthy, however, because other kinds of mouse traps (not flat) with separate spring and striker existed before.
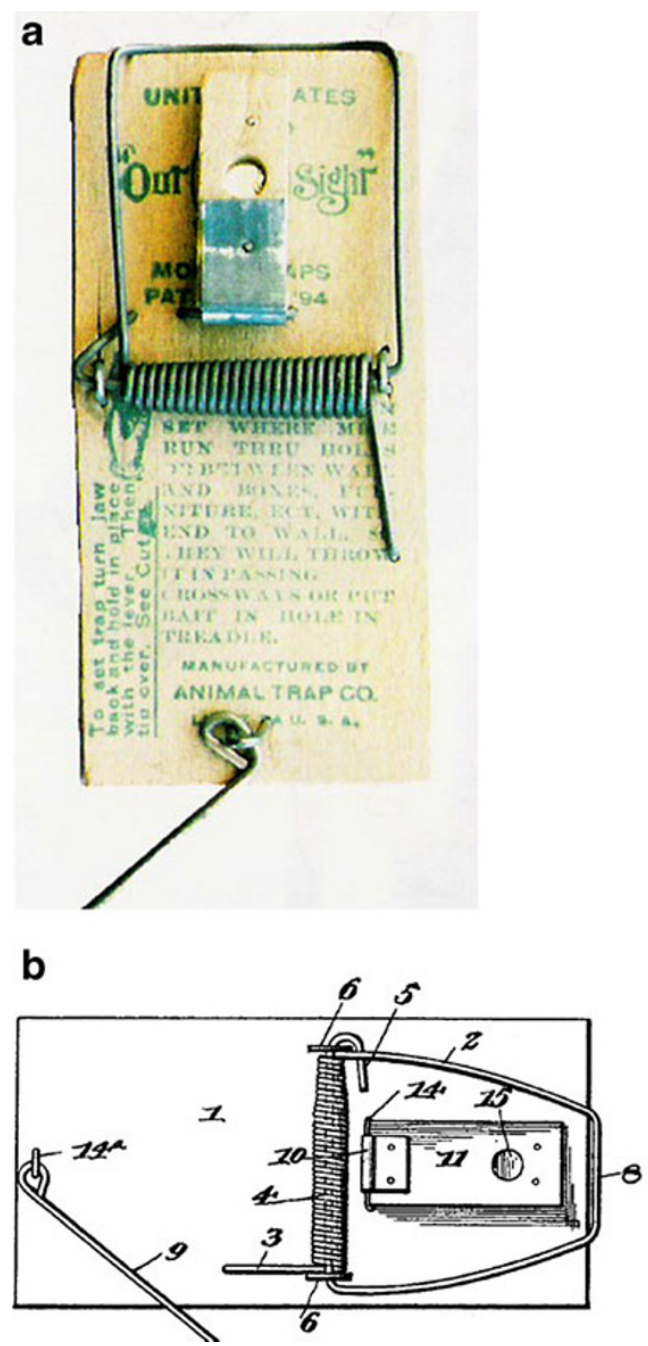

Fig. 1 Hooker's patent. a Antique specimen of the "Out O' Sight" (from Drummond 2005, Fig. 23). b Drawing from the patent of Hooker (1894). The spring/striker wire begins at \#3, coils (\#4), passes into the striker (\#8), runs through the tunnel formed by the coil, and ends behind the striker (\#5). Parts \#6 are fixtures
The common ancestor of all current flat snap traps had one part less, and the great variety of these traps today is due to its success. Therefore, Behe's first conclusion is wrong. Irreducibly complex systems can have working precursors with one part less.

Similar variations in the number of parts occurred throughout mouse trap history. Irreducible complexity is no obstacle to varying numbers of parts by addition, fusion, or separation of parts. The only thing that does not work is taking away a part that carries a function.

\section{Continuous History: The Straight Story}

The ancient Egyptian culture was highly pictorial, and trapping fowl was a royal sport. Catching rodents was no royal sport. Nevertheless, rat cage traps made of pottery are also known from ancient Egypt (e.g., Drummond et al. 1990) and elsewhere. Therefore, the fact that the oldest historical records are bird traps from Egypt cannot be taken to mean that these traps were confined to Egypt or to catching birds.

Twisted fibers powered nets, snares, or clubs with skullcrushing spikes (Lagercrantz 1950). Some ancient bird traps were strikingly similar to flat snap mouse traps (Fig. 2a, b). Grdseloff (1938a) and Scott (1940) feature restored specimens. Grdseloff (1938b) identified hieroglyphs for this trap kind and traced them back into the old kingdom (2686-2181 BCE). Similar traps survived into recent times (Fig. 2c).

Later versions were entirely of wire. Such springloaded wire traps are still used for birds in the Mediterranean region. They were also promoted as rodent traps in the nineteenth century. Ets Julien Aurouze, Paris, has been decorating their shop window with stuffed rats dangling from these traps ever since 1872 (see www.aurouze.fr/deratisation.html). The display has become a tourist attraction also featured in the film Ratatouille. Nevertheless, Aurouze's online catalog lists these traps as Piège à oiseaux (trap for migrating birds).

An advert of Orlando Leggett, Ipswich, and a patent of George Frost (1891) from Toronto, Canada, explicitly call them rat traps. Similar traps were marketed as "bird and mouse traps" in Germany (Drummond and Dagg 2010). While one wire formed handle and spring in Legget's "Cyprus" (Fig. 2d), base-jaw and handle are a unit in Frost's patent (Fig. 2e). In none, however, were spring and striker of one wire.

Here, as elsewhere, the historical record poses the paradox that homologous ideas can be culturally transmitted via analogous structures. The historical context, however, suggests that the traditional clap-bow trap inspired the invention of such a trap entirely of wire and 


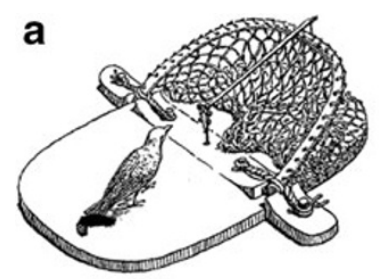

b
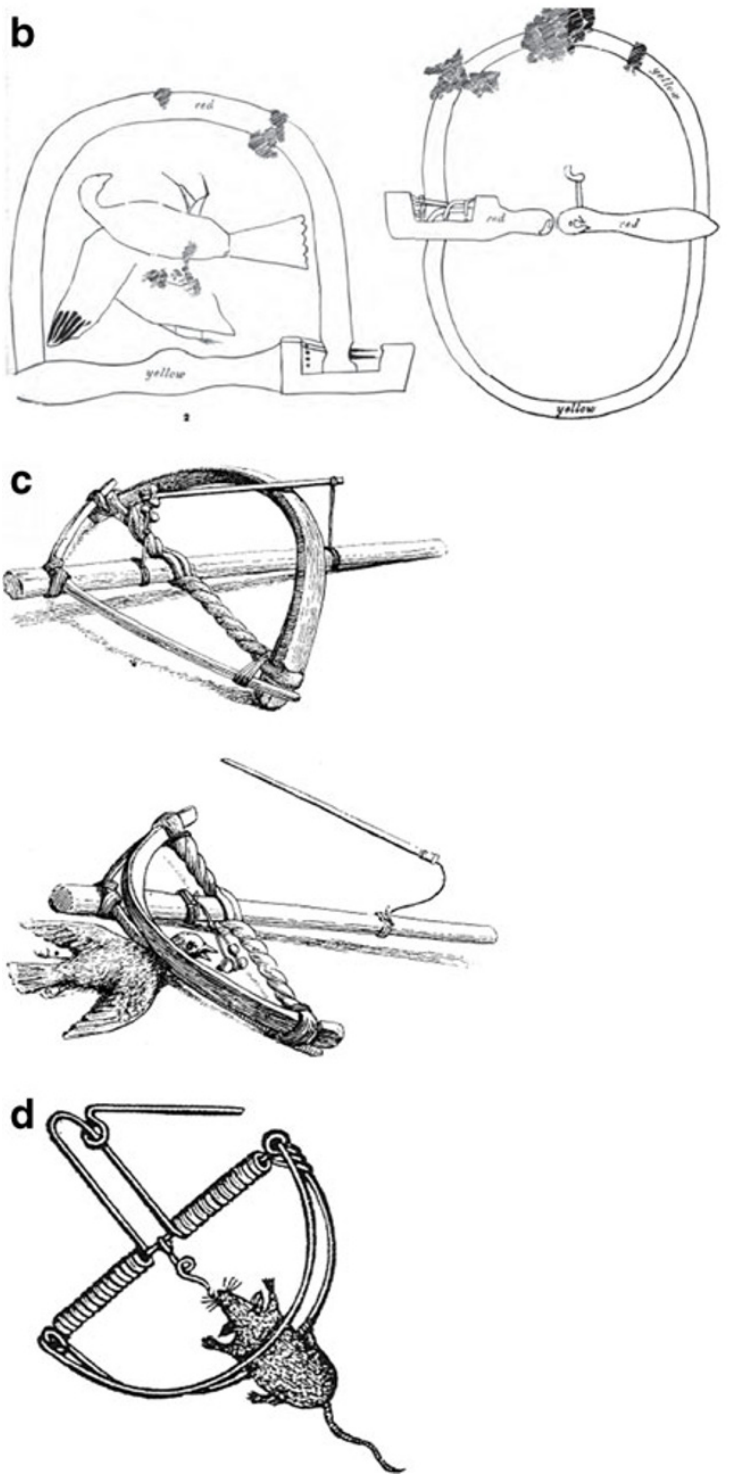

Fig. 2 The straight story. a Reconstruction of an Egyptian clap-net trap for birds of ca. 1550 BCE (from Schäfer 1918/19, Abb. 100). b Torsion trap pictured in tomb 17, of Khety, 2125-1985 BCE (from Griffiths 1900, plate 22). Only one side of the base holds a twisted cord. See also Firth and Gunn (1926, p. 6). c Egyptian clap-bow trap, early nineteenth century (from Schäfer 1918/19, Figs. 91 and 92). d All-wire trap advertised as "Cyprus" by Orlando Leggett, Ipswich, ca. 1890 (from Drummond 2008, Fig. 11). The name might indicate its

its wide sale in the Mediterranean (Schäfer 1918/19). That is, the idea of a flat snap trap has been culturally transmitted. Niles Eldredge (e.g., Tëmkin and Eldredge 2007) refers to the deliberate invention of alternative
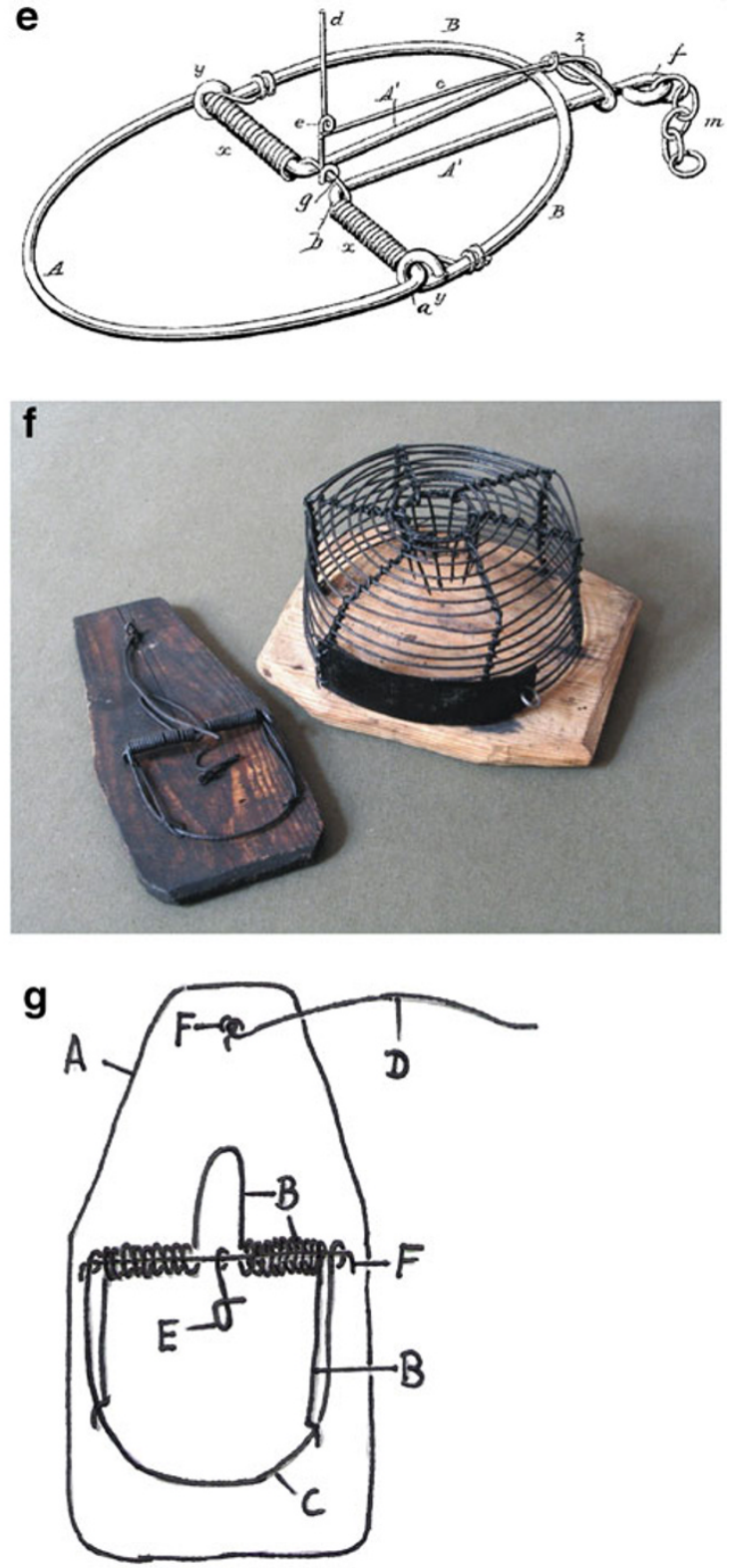

origin in Mediterranean bird traps. e Drawing of all-wire trap patented by Frost (1891). f Specimen of tinker traps, late nineteenth century, Velke Rovne, Slovakia, (www.velkerovne.sk/contents/chod07_sk. $\mathrm{htm})$. g Drawing from this picture. $A$ : wooden platform, $B$ : spring/ handle unit, $C$ : striker, $D$ : holding bar (part of set/release mechanism), $E$ : bait hook (part of set/release mechanism), F: fixtures. Spring/ handle unit, striker, and bait hook resemble Legget's Cyprus rather than Hooker's Out O' Sight

realizations as the "Hannah principle." In the broad sense, the Hannah principle is an extreme case of lateral transfer, when all the parts of a trap system are exchanged at the same time. In the narrower sense, it is an exchange of 
material parts that requires an analogous solution. For example, the twisted cord of torsion traps was replaced by a coiled wire.

The main success (and conservation problem) of this design remains in trapping song birds today (see website of "Lega Italiana Protezione Ucelli"). Maybe birds are particularly unsuspecting against bait sitting on a twig-like wire structure. Its use as a bird trap may also explain why this design has hardly been recognized as belonging in the history of mouse traps. Mounting striker, spring, and set/ release mechanism on a wooden base, however, yields a traditional tinker mouse trap (Fig. 2f, g).

In the nineteenth century, tinkers peddled their goods around the world (Drummond and Dagg 2010). Slovakian tinkers (Drotári) even reached America during tours of up to eight years (Ginzler, unpublished). ${ }^{1}$ From 1870 onwards, an increasing number of Slovaks immigrated into the United States for good. Coincidentally, their favorite destinations were the Northeast and Midwest including Pennsylvania and Illinois.

The tinker trap (Fig. 2f) differs from Hooker's patent. Spring and striker are not formed of one part; the spring has an uncoiled middle part looking like the handle of a Cyprus-like trap (see Fig. 2d, e); the set/release mechanism has a bait hook, as in clap-bow and Cyprus-like bird traps, rather than a pedal.

If specifically cultural ways of information transmission are included, the descent from Bronze Age torsion traps to current flat traps shows no big jumps in design. The exchange of wood and fibers for wire necessitated a change from twisted to coiled power source exemplifying the Hannah principle in the narrower sense. History is as continuous here as later, when tinkers exchanged the base wire-jaw for a wooden platform transforming a veritable bird trap into a veritable mouse trap.

The meta-level question of how the historical records reached us, rather than how the artifacts have been transmitted in the past, reveals reconstructing, reverseengineering, and decoding (language) as further ways of information transmission. This list does not, by far, exhaust the means of time-travel (recovery), which cultural information has (e.g., archiving, excavation, and preservation). Dormant cultural information can jump back into use (Wimsatt 1999). Therefore, continuity of artifact history does not imply a uniformly ticking clock of cultural change.

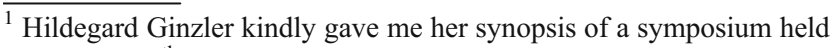
during the $50^{\text {th }}$ anniversary of the Tinker Museum in Zilina, Slovakia, read to the Heritage Club of Neroth, Germany, in 1993.
}

Evolution: All Prerequisites Abound

We are not here considering the question whether mouse trap history is in fact a case of evolution, but whether it cannot be evolutionary in principle, as Behe (1996) claimed.

\section{Variation}

The Animal Trap Company, Lititz, PA produced more than 30 variant snap traps and 13 variant set/release mechanisms (Drummond et al. 2002). Other companies, countries, times, and traps show equal variability (recorded mainly by Lagercrantz 1950, 1964, 1966, 1972, 1984, 1987) and Drummond (2004a, 2005, 2006, 2007, 2008, 2009a, b). For example, Drummond (2005) features over 60 variants of British flat snap mouse traps.

\section{Transmission}

The "Out O' Sight" retained an old design of spring and striker being made of one wire (see Fig. 1). Similar instances of transmission could be provided for other trap kinds. Cyprus-like traps retained the bait hook of ancient torsion and traditional clap-bow traps. Lateral transfers are, of course, also instances of transmission though they cross the categories that users perceive as different kinds of artifacts.

\section{Selection}

For example, the torsion power source using twisted fiber was replaced by wire springs. Mascall's record of 1590 shows that Renaissance torsion traps (Fig. 4) existed alongside traps using an uncoiled wire spring (Fig 5a). Torsion power even survived up to the late nineteenth century in Egyptian clap-bow traps (Fig. 2c; Schäfer 1918/ 19) before the coiled wire spring replaced it. Nowadays, the torsion power source seems to be utterly extinct excepting the possibility of relics in some remote regions.

Differential reproduction can be expressed as the ratio of patents filed to patents used. Unfortunately, inventors do not tend to specify patents further than "animal trap," in order to keep their options open. Drummond (2004b) ${ }^{2}$ identified 4,593 US patents suitable for mouse traps in principle, from which 165 have been used in 149 actually manufactured mouse traps. The

\footnotetext{
$\overline{2}$ This survey excluded patents for glue traps, electrocuters, trap-guns, traps for burrowing animals, traps that deliver a blow by means other than a swinging striker, and jaws or gin traps in which both jaws are strikers moving toward the quarry (as opposed to jaws in which only one jaw strikes).
} 
commercially successful traps, however, used only seven patents. Hence, $4 \%$ of the patents filed were used, and $5 \%$ of the patents used were commercially successful. These figures compare quite well with an estimate in 1869 by US Commissioner of Patents Samuel S. Sparks that $10 \%$ of all patents (not just mouse traps) had some commercial value (Basalla 1988).

Selection among mouse trap patents may be stiffer than among patents in general due to a popular quotation attributed to one of Ralph Waldo Emerson's spring 1871 lectures (Adams 1947): "If a man can write a better book, preach a better sermon, or make a better mouse trap, than his neighbor, though he builds his house in the woods, the world will make a beaten path to his door." Many a mouse trap inventor has been crestfallen to find no such path beaten to his door.

Basalla (1988) showed that cultural values are a crucial ingredient in the success (selection) of artifacts. The name "Out O' Sight" indicates one such value. The trap could be placed were visitors would not see it, unlike the cage traps, chokers, and dead-fall traps dominating the scene before (Hornell 1940; Hellwig, unpublished ${ }^{3}$ ). When mass production took off, its cheapness also allowed to discard the trap along with the dead body, probably a high cultural value to urban dwellers. All earlier trap types required a handling of mice and often a thorough cleaning of the trap for repeated use. As caged mice were usually drowned or starved to death, these traps were less humane than may appear at first sight. Another modern cultural value is the upper surface of flat snap traps as space for advertisement (see Fig. 1a; Drummond et al. 2002).

Interestingly, these cultural values do not concern the trapping function. On the one hand, a flat surface that can be used for advertising is a spandrel (Gould and Lewontin 1979; Sole, this issue). On the other hand, advertisements affect consumer selection, and the availability of such surfaces affects vendor selection.

\section{Part II: Material Culture Evolution}

The remainder of this contribution widens the perspective to include more than one lineage and discuss the implications for material culture evolution.

\footnotetext{
${ }^{3}$ The late Reinhard Hellwig, erstwhile Guinness world record holder for the largest mouse trap collection, held a talk at the fiftieth anniversary of the Tinker Museum in Zilina, Slovakia, in 1992. I refer to a copy of his manuscript handed to me by David Drummond.
}

The Involute Story

If the below evidence is regarded as forming a lineage, lateral transfer necessarily has to bridge the apparent jumps in design. The principle of parsimony suggests to assume as few instances of lateral transfer as possible. This may not be a good principle for mouse trap history after the Emerson effect (see above) occurred in 1871. For the largest part of history, however, it seems quite reasonable.

\section{Ad Hoc Dead-Fall Traps}

Ad hoc traps are built (at least in part) from material found near the spot where they operate. These naturefacts, as Basalla (1988) calls inventions from naturally occurring things, do not tend to leave long-lasting historical records (Hoffecker 2005). That is, they might be much older than their earliest records suggest.

Ad hoc dead-fall traps are of irreducible simplicity consisting of an errant slab or other heavy object as striker, some sticks arranged to hold it up but to give way on disturbance (set/release mechanism), and bait. In the simplest case, the set/release mechanism consists of one stick or other object that also holds the bait. More sensitive set/release mechanisms consist of several sticks and sometimes also string. A "figure-four" arrangement of sticks (Fig. 3a), for example, is very widespread.

Mascall (1590) recorded it as "Samson poste for Rattes." While Mascall's description and illustration might not be clear enough on its own, Lagercrantz (1984) clarified the issue and pointed out that "Samson post" was a common name for figure-four traps. If the striker is a $\log$, the base is usually another $\log$, and upright posts at both sides prevent the striker from missing the base (see Gibson 1880, p. 114).

Lagercrantz (1972) reviews ad hoc dead-fall traps in different cultures with various strikers and a variety of set/ release mechanisms. He features 18 variants of which only one shows the figure-four design of Fig. $3 \mathrm{a}$ and none as Gibson (1880, p. 114).

\section{Prefabricated Dead-Fall Traps}

Prefabricated dead-fall traps are produced independent of the site and time of operation. Base and striker are often boards. A wooden bar (latch) and a treadle functioned as set/release mechanism. Leonard Mascall (1590) recorded this design as the "Square mouce trappe" (Fig. 3b).

Illuminations in manuscripts of the fable Mashal haKadmoni from 1450-58 also show this design (Roth 1956, 
a

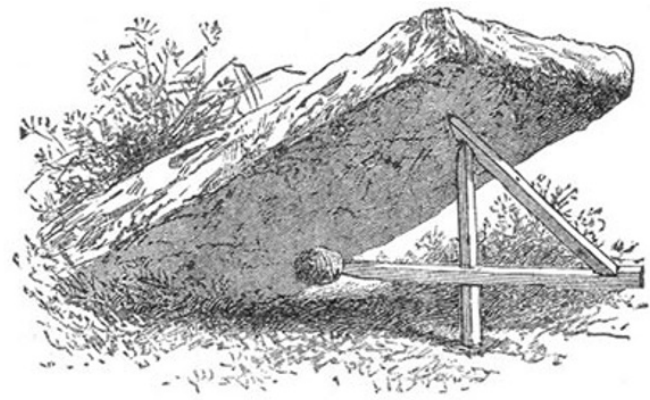

b

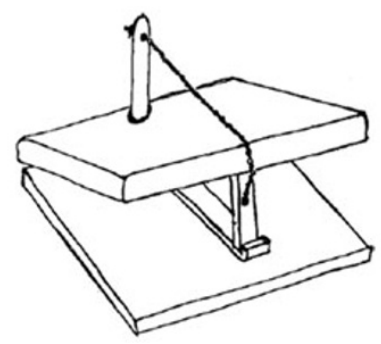

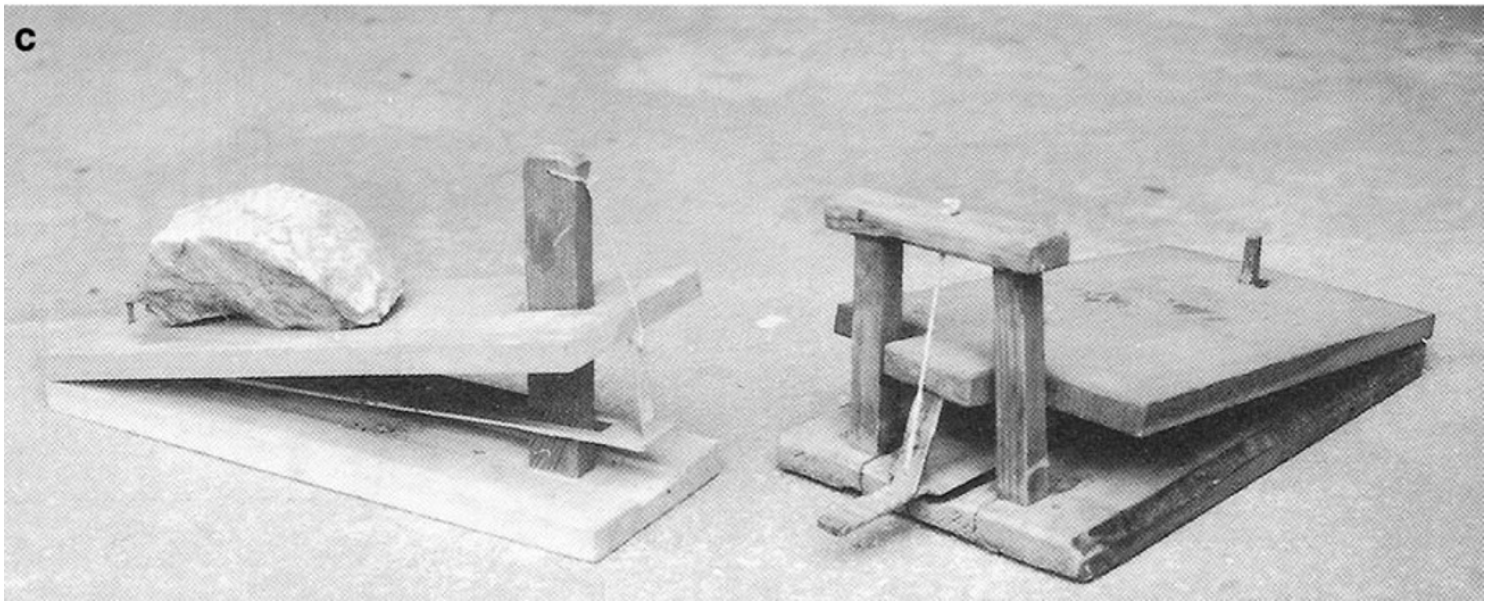

Fig. 3 Dead-fall traps. a Ad hoc "figure-four" trap (from Gibson 1880, p. 107). b Prefabricated "Square mouce trap" (recorded by Mascall 1590. Reconstruction from Drummond 1992, Fig. 1f). c Specimens of prefabricated dead-fall traps from Tyrol (from Gasser 1988, Fig. 44)

plate XIV b, c). Antique specimens from Tyrol show two variants (Fig. 3c): in the left one, the upright post holding the string with the latch is relocated towards the front; in the right one, it is replaced by two upright posts and an overhead beam forming a frame.

An illumination of the Mashal ha-Kadmoni of 1458 also has an overhead beam (Roth 1956, plate XIV d), and further antique specimens survived in Scandinavia (Berg 1966). Lagercrantz (1984) features over 30 variants of prefabricated dead-falls.
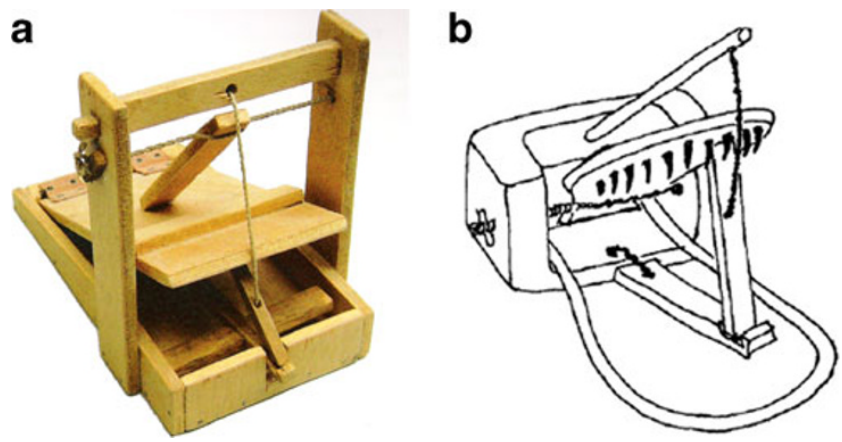

Fig. 4 Renaissance torsion traps, a Mérode or "Following" trap (recorded by Master of Flemalle, 1425, and Mascall 1590). Replica from Drummond (2005, Fig. 18). b Mascall's "Dragin trappe" (from Drummond 1992, Fig. 2b). A twisted cord powered the striker

\section{Renaissance Torsion Traps}

Calling the following Renaissance torsion traps is not just a temporal classification but also hints at torsion traps from antiquity (see "The Straight Story" above). In Fig. 4a, the frame also holds a twisted cord powering a wooden rod that presses on the striker. Mascall (1590) recorded this design as the "Following trappe," because he called the rod pressing on the upper board the "following staffe." It has become famous as the "Mérode mouse trap," because the right wing of the Mérode altar triptych of circa 1425 shows such a trap on St. Joseph's workbench (Web Gallery of Art 2010 provides an online image with zoom function).

Zupnick's (1966) curious claim that the item in question is a carpenter's plane rather than a mouse trap has been disproved beyond doubt (Berg 1966; Eisler 1966; Nickel 1966; Shapiro 1966; Drummond 1997a). A replica made by a carpenter of the Walker Art Gallery, Liverpool, even caught a mouse (Jacob 1966).

In another Renaissance torsion trap, the twisted cord sits at the pivot and the striker is inserted directly into the twisted cord (Fig. 4b). Mascall (1590) recorded this design as "Dragin trappe for Mice and Rattes." Master Casper's woodcut "Frau Venus und der Verliebte" (ca. 1485) shows 
a

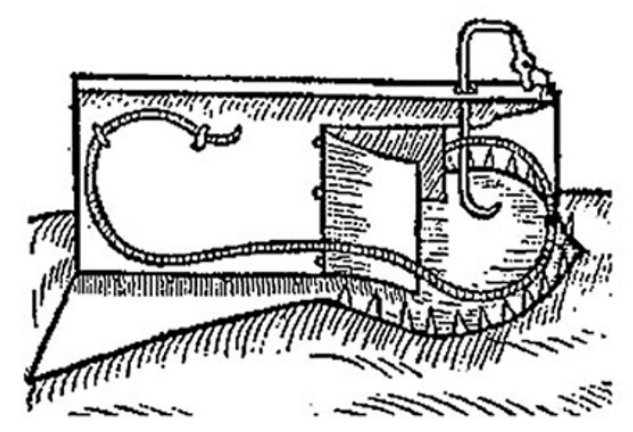

b

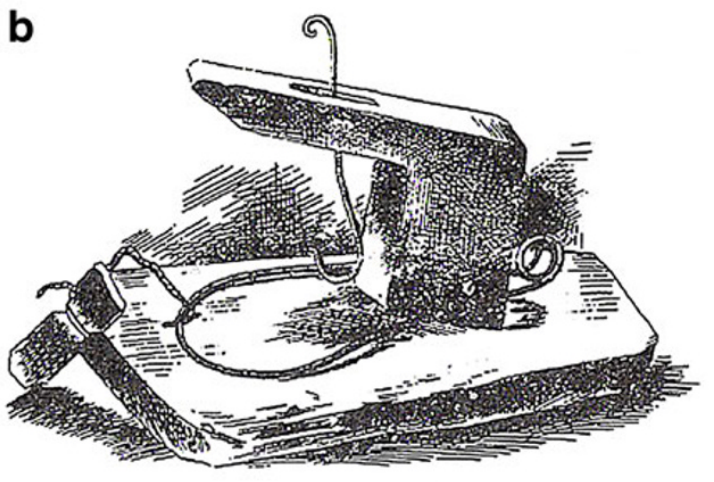

C

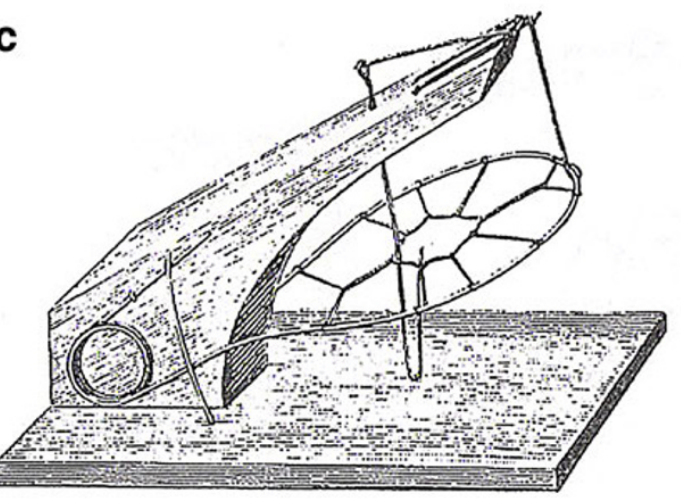

d

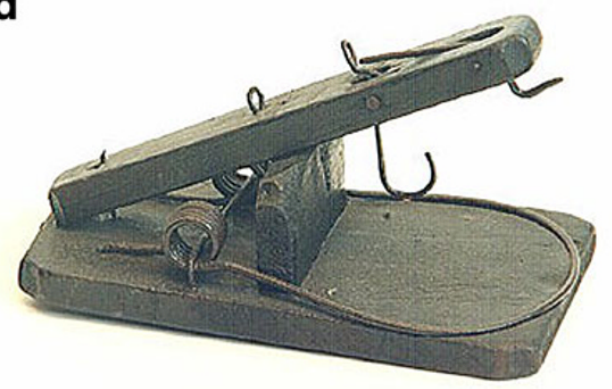

Fig. 5 Traps with spring and striker made of one wire. a Left: "Dragin trappe with great wyar" from Mascall (1590, p. 75); right: replica from Drummond (2005, fig. 19b). b Polish "Planchette" (modified from Lagercrantz 1987, Fig. 5). c French "Planchette" (modified from Lagercrantz 1987, Fig. 4). d Victorian "Break back" (from Drummond 2008, Fig. 12e). e Horace Tinker's "Little Giant" patented in 1882 (from
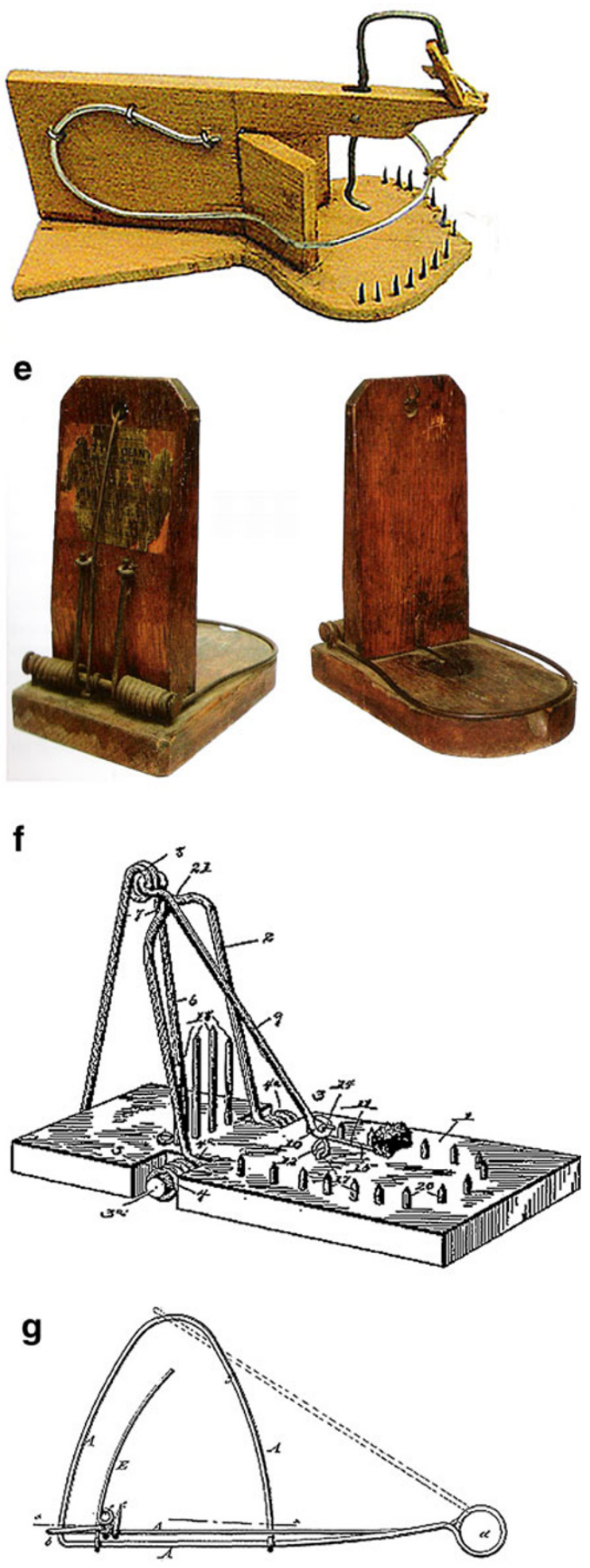

Drummond 2009b, Fig. 1)., f Drawing from Anderson (1890, see also Castle 1888, Andrews 1891, Troumble 1892, Wells 1892). g Drawing from Hooker (1879). Mole trap with frame $(A, g, A, A)$, spring $(d)$, and striker $(A, b, e)$ made of one wire (from Hooker 1879). When the bait hook $(E)$ is moved to the left, the striker snaps upwards (dotted line) 


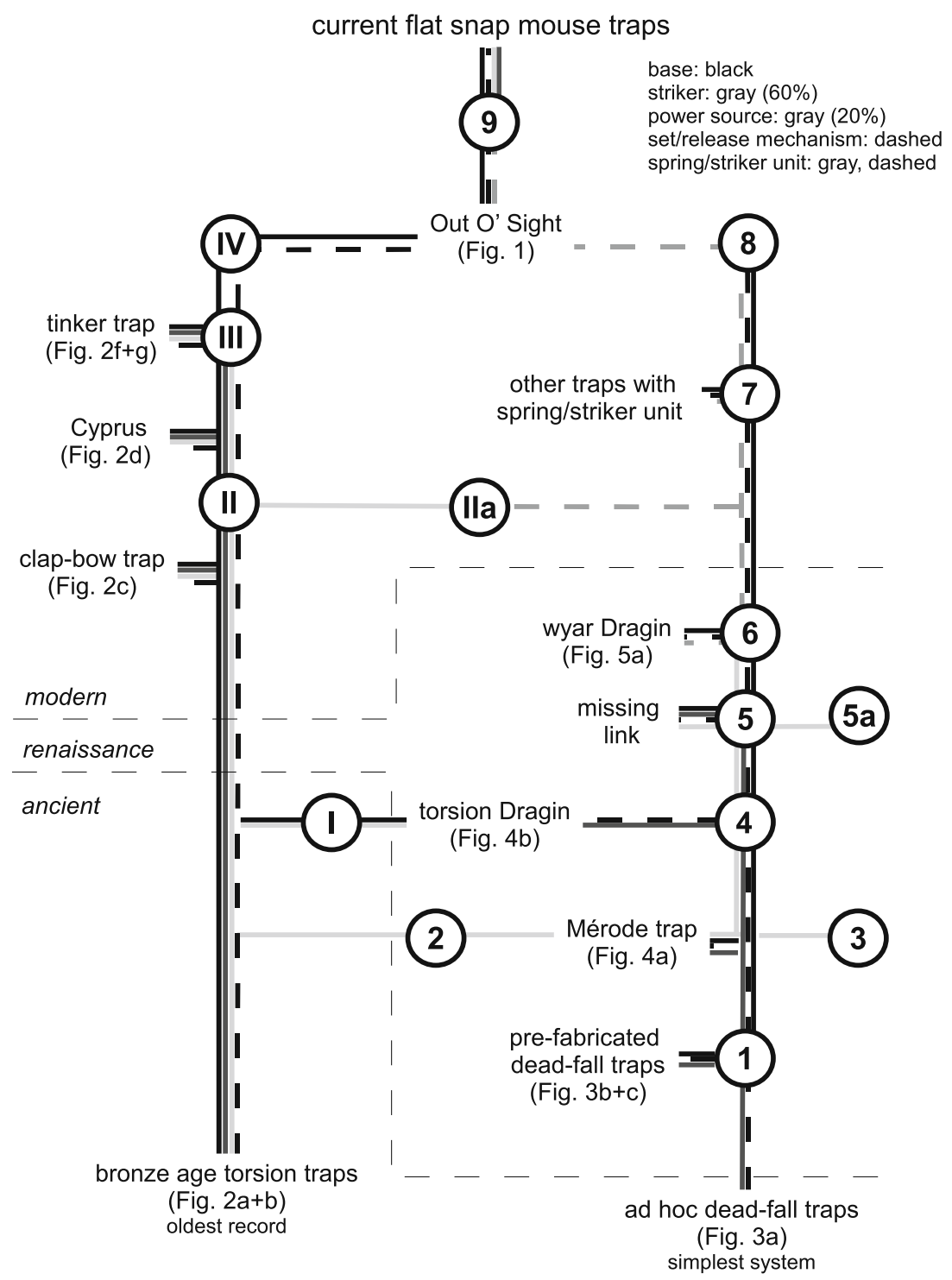

Fig. 6 Synopsis. Simplified history, each line stands for the lineage of a part: base in black; power source in light gray; striker in dark gray; set/release mechanism dashed; spring/striker unit in gray dashed. Important events: 1 : add wooden base and overhead beam, modify set/ release mechanism; 2 : transfer twisted cord laterally; 3: add following staffe; 4: modify frame, replace twisted cord to pivot, insert striker directly; 5: replace twisted cord by wire spring with striker board fixed to looped middle part, change set/release mechanism; $5 a$ : lateral transfer of wire spring; 6 : reduce striker board and modify middle loop

such a trap in the upper left (high-resolution reprint in Nickel 1966), and a Mashal ha-Kadmoni illustration of 1450 shows a double version (Roth 1956, plate XIVa). Many antique specimens varying this design survived as "Nordo-Baltic" torsion traps (Lagercrantz 1964).

Though most have a frame with a bow as lower opponent to the striker (see Fig. 4b), some have a board instead. "Uralo-Siberian" torsion traps (see Lagercrantz 1964) differ in striker and set/release mechanism, but most share the bow in the base, though some variants get along of spring to yield spring/striker unit, change set/release mechanism; 7: coil spring, modify frame and set/release mechanism; $8:$ reduce frame to flat base, modify set/release mechanism; 9: divide spring/striker unit into separate parts; I: replace clap-bow by striker board, modify frame, change set/release mechanism; II: Hannah principle: replacement of wood and fiber by metal parts (lateral transfers not shown); IIa: Transformation of spring/striker into spring/handle unit (see 'A part's eye-view' below); III: mount striker jaw, spring, and set/release mechanism on oblong wooden base; $I V$ : Replace bait hook by treadle

without it because the lower opponent to their striker (a club with spikes) sits at the other side of the base and the striker moves 180 degrees. The bow in the base is probably a heritage from much older "clap-bow" traps (see above) suggesting that the bow got transferred along with the torsion power source. This trap could be regarded as a hybrid with the torsion power source and bow in the base stemming from ancient clap-bow traps (Fig. 2b), while the striker and set/release mechanism come from prefabricated dead-fall traps. 
Traps with Spring and Striker Made of One Wire

Narrow-Angled In the "Dragin trappe with a great wyar" (Mascall 1590; Crouch 1647; see Appendix 1), a curved but not coiled wire, is both striker and spring (Fig. 5a).

Later variants, called "Planchette" or "Assomoir grillagé," had a wire with coiled ends (Fig. 5b). Again, church history provides an early record (Tanner 1694; Lagercrantz 1987). An illustration can also be found in a book on how to avoid traps of litigation (Döhler 1723). Scans of both prints are provided as Appendix 2 and Appendix 3. Another variant hinged the striker with two jointed wire bars (Fig. 5 c).

In Victorian specimens (Fig. 5d), a bent wire served as locking bar carrying the functions of both latch and string. Variants of these designs have been patented later (e.g., Herbert 1877, 1881; Leibold 1879; Lewthwaite 1879; Rice 1879; Piggot 1898).

L-shaped Sidney Earl $(1877,1879)$ of Corry and Horace Tinker (1882) of Meadville, PA, patented L-shaped rat traps retaining the spring/striker unit (Fig. 5e). They only claim improvements, probably on earlier L-shaped traps (e.g., Wright 1860).

Henry Anderson (1890) of Whitesborough, TX, patented an intermediate between L-shaped and flat snap trap with spring/striker unit (Fig. 5f). A similar design has been produced in the village Neroth in the German Eifel-region (Drummond and Dagg 2010). The reason for not bending the striker over backwards by 180 degrees might lie in springs with too narrow a range of elastic deformation risking plastic deformation.

Flat In Hooker's (1894) design, one wire still forms both spring and striker (Fig. 1), although only one end is coiled and the straight end passes through the coil tunnel.

\section{Other Potential Sources of Inspiration}

While patents hardly mention sources, further candidates for inspiring Hooker exist. Gamos Richardson (1874) of San Jose, CA, patented a flat snap trap, whose striker presses the victim against a loop, thus choking it. Four loops made sure that the mouse would be throttled no matter from which direction it approached the bait.

Hooker (1879) patented a mole trap with spring, striker, and frame of one wire. Only, the set/release mechanism was made of a second wire (Fig. 5g). Another source from a culture that did not protect intellectual property is detailed above (see Fig. 2f, g).
Synopsis

Figure 6 shows a synopsis leading to the oldest historical record and the simplest trap system. These are not the only lineages that could be gleaned from the historical record. On the contrary, a comprehensive picture would show a network starting with a range of ancient traps and other artifacts, all connected by lateral transfer (recombination of parts), and tracing their reticulate phylogeny towards a range of modern traps and other artifacts. This network should be imagined as forming the background matrix of Fig. 6. The important conclusion for material culture evolution is not whether Fig. 6 depicts all lineages (it does not), but that it depicts lineages of descent rather than arbitrarily construed sequences.

\section{A Part's Eye-View}

The wire spring is an easily identifiable part. As mentioned above, the simplest wire springs are rather straight but bent in set position. Such simple springs, though made of wrought iron, can also be found in gin traps (Haddon-Riddoch 2006). The wire spring enters the involute mouse trap record with curved ends and a middle loop used as striker (Mascall 1590, see Fig. 5a). The ends get increasingly coiled (Crouch 1647; Tanner 1694; Döhler 1723 and Fig. 5b-d). In the nineteenth century, the wire spring enters the straight record already coiled (Schäfer 1918/19), but the middle part is either used as a handle (Fig. 2d) or as a fixture for the bait hook (Fig 2e). Eventually, Hooker (1894) patented the seminal flat snap trap, which had a spring/striker unit but only one end coiled and the other running through the coil.

Four different conditions of the spring part exist in these traps (Fig. 7). Condition $a$ can change into condition $b$ by a reduction of the middle loop. Condition $a$ can also change into condition $c$ by widening the middle loop and folding the coiled ends inward. Finally, condition $c$ can change into condition $d$ by elongating the coil of one end and uncoiling the other end at the same time, running the straight end through the coil. Hence, the parsimonious relationship is: $b-a-c-d$. This lineage can be rooted near $c$ because this condition can easily change into the one of the wyar Dragin by reducing the coils of both ends until only one curve remains at each. As that is the oldest record of a wire spring in mouse traps with one pivoting striker (Mascall 1590), it is probably the ancestral condition.

Other lineages would require far more transformations and, therefore, be less parsimonious. For example, changing condition $b$ into $d$ would require enlarging and widening the middle loop, folding the coiled ends inward, uncoiling one end, elongating the coil of the other end, and running the straight through the coil end. 
A similar part's eye-view on the set/release mechanism would require an excursion into cage traps that is beyond the scope of this contribution.

\section{Discussion}

The first part showed: (1) The patented and seminal precursor of current flat snap mouse traps had one part less. (2) Mouse trap history is continuous. (3) The prerequisites of evolution abound in mouse trap populations. These statements do not apply to trap making. Trap history may be evolutionary despite intelligent humans or intelligently programmed robots producing individual traps. An evolutionary perspective on artifact history alters expectations and induces a search for precursors in the first place.

The second part dealt with the question of whether an evolutionary account of mouse trap history has academic merit beyond its educational value. The straight story of part I (Refuting Behe's Triple-Jump Conclusions) traces only one lineage. While a comprehensive account of mouse trap history would include all the records, it is beyond the scope of this article. Instead, I focused on traps that have one pivoting striker and neglected other trap kinds (e.g., with one striker falling down vertically, with two moving strikers, cage traps, chokers, gun traps, etc.). Eventually, an evolutionary account of mouse trap history must be able to accommodate all trap kinds. Widening the perspective to include traps with one pivoting striker is a first step to see which challenges must be met.

\section{Branching and Reticulate Phylogeny}

Branching phylogenies have been reconstructed for projectile points, words, and other artifacts (reviewed in Collard et al. 2006). For several reasons, descending transfer may seem to be a prerequisite for and lateral transfer to be mutually exclusive with these branching phylogenies. Stone points, for example, show branching phylogeny (O'Brien et al. 2001), and lateral transfer is impossible because each is made of one part. Phylogenies of DNA and words are not only branching but also largely parallel (reviewed in Cavalli-Sforza 1997). The source used for language trees (an early edition of Ruhlen 1991) explains the method of inferring language relations by comparing basic words like: "one, two, three, ear, nose, tooth." Unlike foreign words, basic words descend along the lineages of languages. Likewise, the analyzed DNA was not viral or from transposable elements.

On the other hand, mouse traps consist of several parts that are frequently recombined. The only constraints on lateral transfer are functionality and purpose. Nevertheless, their reticulate phylogeny may resolve as branching, but overlapping, phylogenies of their parts, if true blending does not occur. The fusion of two parts does not qualify as blending, because a part carrying two functions is not the same as a part with an average function, and a later separation of functions/parts remains possible.

Hence, the interesting question is whether branching sub-systems can be isolated from traps. Indeed, a part's eye-view on the wire that carries the function of the power source suggests a branching tree as its parsimonious phylogeny (Fig. 7). In conclusion, the choice between branching or reticulation (e.g., Moore 1994; Bellwood 1996; Collard et al. 2006) may be a false dilemma. As long as lateral transfer only means recombination of parts and not true blending, a reticulate phylogeny should resolve as overlapping, but branching, phylogenies of parts.

\section{Likely Instances of Lateral Transfer}

Torsion power may have been transmitted laterally from Egyptian torsion traps to prefabricated dead-fall traps. A simple addition of twisted cord and following rod would have transformed a prefabricated dead-fall trap with overhead beam (Fig. 3c, right specimen) into the Mérode mouse trap (Fig. 4a). The simplicity of this addition does not exclude the possibility of convergent invention. In the absence of further evidence, however, lateral transfer via a diffuse culture pool is more parsimonious.

The "Dragin" torsion trap cannot be regarded as a simple addition of torsion power to a dead-fall trap. Its base is similar to that part of the tomb-of-Khety trap (Fig. 2b), which holds the torsion power source. Stretching this side of the base and shrinking the other could transform the tomb-of-Khety base into that of the torsion "Dragin" trap. The striker and set/ release mechanism of the torsion "Dragin" are as in prefabricated dead-fall traps, while inserting the striker into a twisted cord and the bow in the base are as in ancient Egyptian torsion traps. This hybrid nature of the torsion "Dragin" trap makes convergent invention seem less likely.

Mascall's two "Dragin" traps comprise the gap between twisted cord (Fig. 4b) and wire spring as power source (Fig. 5a). An uncoiled wire spring was also used in chokers (Mascall 1590). Simpler choker traps and snares had flexible poles or saplings as springs (Lagercrantz 1966, plate 2a). Once available, wire should have been an obvious improvement of chokers, and lateral transfer between two kinds of trap from the same era seems quite likely.

The set/release mechanism changed from suspended strikers with a treadle (Fig. 4b) to hinged strikers with a bait hook (Fig. 5a). Again, the "Dragin" traps comprise this lateral transfer. The second transfer was from hinging the 


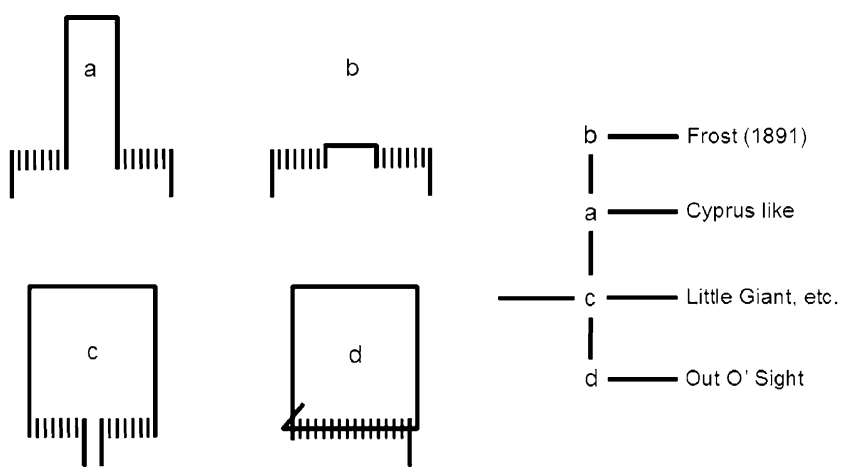

Fig. 7 A part's eye-view: relations between spring wire conditions. Dashed lines represent coiled parts of the wire that carries the spring function. a Spring/handle unit as in Legget's Cyprus from 1891 or in tinker traps from the late nineteenth century. b Spring/fixture unit as in Frost (1891). c Spring/striker unit as in "Planchettes," "Break Back," "Little Giant" (Tinker 1882), or even in the "wyar Dragin" trap, if the coils of the ends are reduced to one curve each. d Spring/striker unit as in the "Out O' Sight" (Hooker 1894). As explained in the text, the parsimonious relationship is $b-a-c-d$. The likely root at $c$ yields a branching phylogeny, which includes a lateral transfer $(c \rightarrow a)$

striker with a string plus latch to hinging it with a locking bar. The "Planchettes" comprise this change. While the striker of the Polish "Planchette" (Fig. 5b) was still hinged with latch on string, that of the French (Fig. 5c) was hinged with a locking bar.

Ancient Egyptian torsion traps already hinged the striker with a locking bar and bait hook (Fig. 2a; Schäfer 1918/19). Bait hooks and locking bars were also used in choker traps (Drummond 1997b, 2005), where they constituted considerable improvements of the earlier set/ release mechanism: a thread whose setting was fiddly and that was released by the mouse gnawing it through in order to reach the bait.

An extreme case of lateral transfer occurred in the "Hannah replacement" of wood and fiber by metal parts between Egyptian clap-bow (Fig. 2c) and Cyprus-like traps (Fig. 2d, see also event II in Fig. 6).

\section{Lateral Transfer Leads to Cumulative Evolution}

Boyd and Richerson (1996) argued that the capacity for observational learning (imitation) is a prerequisite for culture to become cumulative. Without observational learning, every individual needs to learn from scratch. In that way, the ability to produce stone flakes could spread through a population, but no more sophisticated technology could evolve from it. Models of cultural evolution through imitation are troubled, however, by the infidelity of cultural transmission (e.g., Henrich and McElreath 2003). Therefore, imitation is necessary but not sufficient for cumulative cultural evolution.
The above evidence on traps suggests that the ability to (re)combine artifacts is also necessary for culture to be cumulative. Suppose that Stone Age people used stone flakes, bone chips, sticks, fiber strings, and other simple tools but never combined them into spears, arrows, bows, nets, fishing rod and line, etc. No cumulative evolution of material culture would have occurred. Thus, the recombination of parts (i.e., lateral transfer), which is usually seen as a major obstacle to phylogenetic reconstruction of culture, turns out to be part of the solution to the question why culture is cumulative.

An experimental study of chimpanzee behavior supports this conclusion. Marshall-Pescini and Whiten (2008) have shown that chimpanzees tend to get stuck with a learned technique (behavior) for gaining food, even though a slight restructuring of the technique would yield vastly improved gains. The restructuring concerned the technique with which a tool (rod) was used rather than the tool itself. This suggests that an aptness of humans for recombining mental structures makes the difference between cumulative and non-cumulative cultures. By extrapolating from mental to physical recombination, this result also bears on artifact evolution.

\section{Extended Phenotype or Diversified Information}

Another question of interest is whether an evolutionary account of material culture as an extended phenotype is sufficient. The differentiation of ways for transmitting cultural information should also be included, because the big difference between cultural and biological evolution does not lie in phenetic diversity but in the diversity of ways of information transmission (Wimsatt 1999).

The historical records from part I.3 (Continuous History: The Straight Story) already showed the importance of reconstructing, reverse-engineering, decoding, and the Hannah principle as means of cultural transmission. Increasingly complex artifacts require increasingly sophisticated means of transmitting cultural information. While able craftsmen may still reconstruct a working Mérode trap from its artful depiction in the Mérode altar-piece, no individual could reproduce a computer that way.

Acknowledgments Thanks to Hildegard Ginzler for an unpublished manuscript and Babette Ellen Kottkamp for a documentary film on the last Slovakian tinkers, but most of all to David Drummond for much help and comments on the manuscript. Figures 1a, 2d, 3b, 4a, b, and $5 \mathrm{a}, \mathrm{d}$, e, appear courtesy of David Drummond; Fig. 3c appears courtesy of Christoph Gasser, and Fig. 2f appears courtesy of Jozef Mičieta, mayor of Velke Rovne. The rest are either the author's or public domain. 


\section{Appendix 1}

Section from Crouch (1647). Though vaguely drawn, the peculiar form of the striker suggests a "Dragin trap with great wyar."

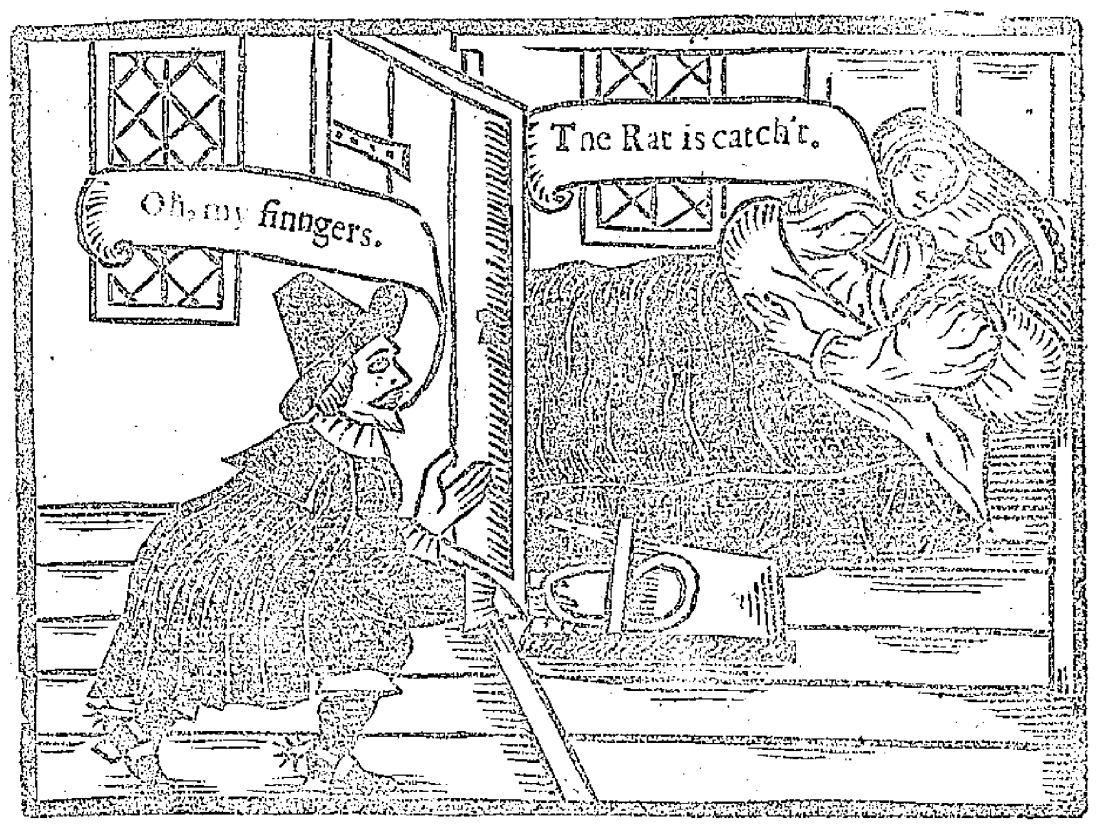




\section{Appendix 2}

Print from Tanner (1694). The "Planchette" is in the white frame.

\section{P. Henricus Schachtius. TgS}

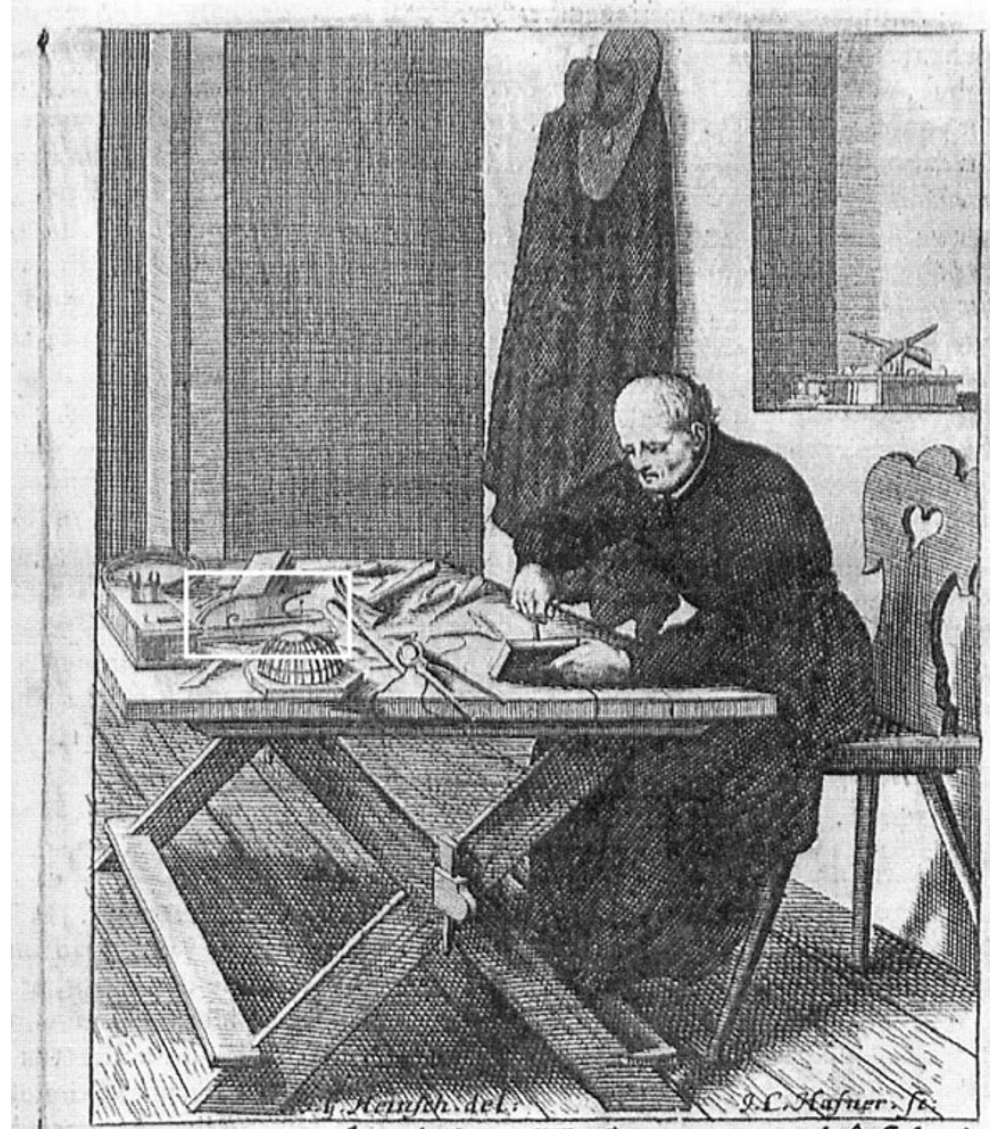

P. Henricus Schachtius, SI. Germanus, vitâ faluti proximorum afferenda confecratâ, ut incognitus eam fecurig proctraret, mof cipularum artificem fimulavit. Capt ${ }_{9}$, et eqvuleo ter excruciat, atg $q_{3}$ e

stecia profreniptg, decessit Hamburgiz.Ian:165" at:7t. 


\section{Appendix 3}

Print from Döhler (1723). The "Planchette" sits at the bottom right.

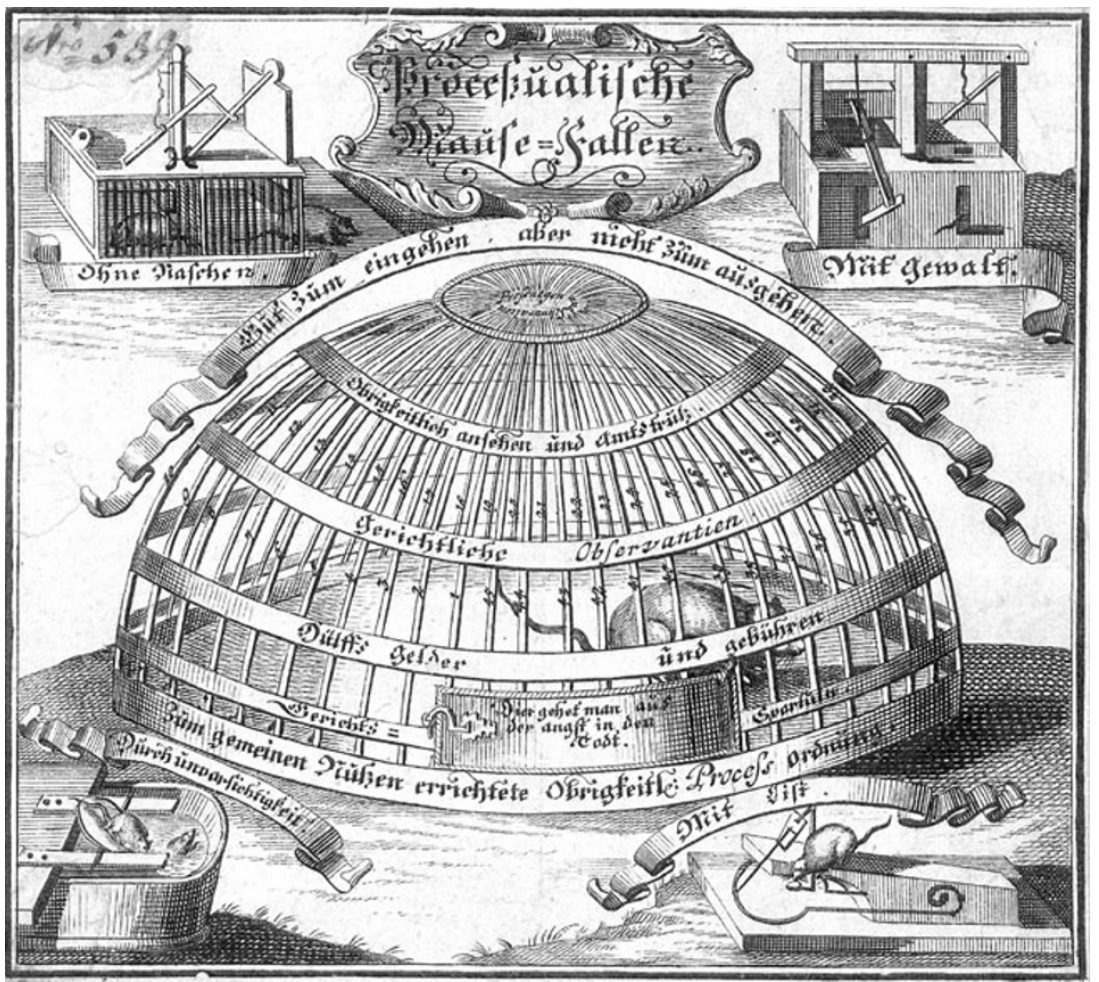

\section{References}

Adams R. Emerson's brother and the mousetrap. Mod Lang Notes. 1947;62:483-6.

Anderson HC (1890) Animal-trap. Patent no. 434,751. United States Patent Office.

Andrews G (1891) Animal-trap. Patent no. 465,011. United States Patent Office.

Basalla G. The evolution of technology. Cambridge: Cambridge University Press; 1988.

Behe MJ. Darwin's black box. New York: Free Press; 1996.

Bellis M (2009) History of the mousetrap. Available at: http:// inventors.about.com/od/mstartinventions/a/mousetrap.htm. Accessed on: 2 Sept 2009.

Bellwood P. Phylogeny vs reticulation in prehistory. Antiquity. 1996; 70:881-90.

Berg G. Medieval mouse traps. Stud Ethnogr Ups. 1966;26:1-13.

Boyd R, Richerson PJ. Culture and the evolutionary process. Chicago: Chicago University Press; 1985.

Boyd R, Richerson PJ. Why culture is common but cultural evolution is rare. Ethol Sociobiol. 1996;16:125-43.

Castle WH (1888) Animal-trap. Patent no. 391,118. United States Patent Office.

Cavalli-Sforza LL. Genes, people, and languages. Proc Natl Acad Sci USA. 1997;22:7719-24.

Cavalli-Sforza LL, Feldman MW. Cultural transmission and evolution. Princeton: Princeton University Press; 1981.
Collard M, Shennan SJ, Teherani JJ. Branching, blending, and the evolution of cultural similarities and differences among human populations. Evol Hum Behav. 2006;27:169-84.

Crouch H. Come buy a mouse-trap, or, a new way to catch an old rat. Being a true relation of one Peters a Post of Roterdam [...]. London: Iohn Hammond; 1647. Early English Books Online, accessed 16 Sept 2009.

Döhler JG (1723) Processualische Mause-Fallen, oder, Kürtzliche Vorstellung wie es bey Processen insgemein her zu gehen Pflege? und was man gutes darbey zu haffen habe? Verlegts Paul Günther Pfolenhauer und Sohn, Coburg.

Drummond DC. Unmasking Mascall's mouse traps. Proceedings of the Fifteenth Vertebrate Pest Conference 1992. DigitalCommons @ University of Nebraska, Lincoln; 1992. Available at: http://digital commons.unl.edu/vpc15/23/. Accessed on: 12 Dec 2008.

Drummond D. The Mérode mouse trap and the missing clicket. Tools Trades. 1997a; 10:37-42.

Drummond D. 'Irish' mouse traps. Folk Life. 1997b;35:54-62.

Drummond D. Nineteenth century mouse traps patented in the U.S.A. Galloway: North American Trap Collectors Association; 2004a.

Drummond DC. Better mouse traps: the history of their development in the USA. In Fagerstone KA, Witmer GW editors. Proc 10th Wildlife Damage Management Conference; 2004b. p. 388-397.

Drummond D. Mouse traps: a quick scamper through their long history. Galloway: North American Trap Collectors Association; 2005.

Drummond D. McGill mouse traps and the Stilson brothers. A commercial success in Marengo, Illinois. Galloway: North American Trap Collectors Association; 2006. 
Drummond D. Twentieth century mouse traps patented in the U.S.A.: 1900-1924. Galloway: North American Trap Collectors Association; 2007.

Drummond D. British mouse traps and their makers. Dorking: Mouse Trap Books; 2008.

Drummond D. Twentieth century mouse traps patented in the U.S.A. The last 50 years. Galloway: North American Trap Collectors Association; 2009a.

Drummond D. Norway rat, Erie Canal \& Little Giant. The curious history of robust wooden L-shaped rat traps in the U.S.A. Galloway: North American Trap Collectors Association; 2009b.

Drummond D, Dagg JL. Neroth mouse traps and their makers. The history of a cottage industry near the German Rheinland. Galloway: North American Trap Collectors Association; 2010.

Drummond DC, Janssen RM, Janssen JJ. An ancient Egyptian rat trap. Mitteilungen des Deutschen Archäologischen Instituts, Abteilung Kairo 1990;46:91-98

Drummond D, Brandt C, Koch J. William C. Hooker's great American mouse trap: its survival and successful development in Lititz, Pennsylvania. Galloway: North American Trap Collectors Association; 2002.

Earl S. Improvement in animal-traps. Patent no. 192,980. United States Patent Office; 1877.

Earl S. Improvement in animal-traps. Patent no. 214,119. United States Patent Office; 1879.

Eisler C. The Mérode mousetrap. Burlington Mag. 1966;108:430.

Firth CM, Gunn B. Excavatons at Saqqara, Teti pyramid cemeteries. Le Caire: Institut Francais d'Archéologique oriental; 1926.

Frost GJ. Animal-trap. Patent no. 459,163. United States Patent Office; 1891

Gabora L. The fate of evolutionary archaeology: survival or extinction? World Archaeol. 2006;38:690-6.

Gasser C. Trappln, Gschuicher und andere Fourtl. $\mathrm{Zu}$ Geschichte, Entwicklung und Ergologie von Abwehrmaßnahmen und Fanggeräten aus dem Raum Tirol. Schriften des Landwirtschaftlichen Museums Brunnenburg, N.S. 1988;2, Dorf Tirol.

Gibson WH. Camp life in the woods and the tricks of trapping and trap making. Project Gutenberg E-book: http://www.gutenberg. org/etext/17093. Accessed on: 31 Aug 2009; 1880.

Gould SJ, Lewontin RC. The spandrels of San Marco and the panglossian paradigm: a critique of the adaptationist programme. Proc R Soc Lond B. 1979;205:581-98.

Grdseloff B. Zum Vogelfang. Zeitschrift für ägyptische Sprache und Altertumskunde. 1938a;74:52-5.

Grdseloff B. Zum Vogelfang im alten Reich, ein Nachtrag. Zeitschrift für ägyptische Sprache und Altertumskunde. 1938b;74:136-9.

Griffiths FL editor. Beni Hasan, part IV. Zoological and other details. Special publication of the Egypt Exploration Fund, London; 1900.

Haddon-Riddoch S. Rural reflections. A brief history of traps, trapmakers and gamekeeping in Britain. Glendaruel: Argyll Publishing; 2006.

Henrich J, McElreath R. The evolution of cultural evolution. Evol Anthropol. 2003;12:123-35.

Herbert PE. Improvement in animal-traps. Patent no. 191,052. United States Patent Office; 1877.

Herbert PE. Animal-trap. Reissued patent no. 9,867. United States Patent Office; 1881

Hoffecker JF. Innovation and technological knowledge in the Upper Palaeolithic of northern Eurasia. Evol Anthropol. 2005;14:18698.

Hooker WC. Improvement in animal-traps. Patent no. 218,532. United States Patent Office; 1879.

Hooker WC (1894) Animal-trap. Patent no. 528,671. United States Patent Office
Hope J. A better mousetrap. American Heritage Magazine 1996;47(6). Available at: http://www.americanheritage.com/articles/magazine/ ah/1996/6/1996_6_90.shtml. Accessed on: 8 Nov 2008

Hornell J. Old English dead-fall traps. Antiquity. 1940;14:395-403.

Jacob J. The Mérode mousetrap. Burlington Mag. 1966;108:373374.

Jenkin F. Review of the origin of species. N Br Rev. 1867;46:277318.

Lagercrantz S. Contribution to the ethnography of Africa. Stud Ethnogr Ups. 1950;1:103-12.

Lagercrantz S. The Nordo-Baltic torsion traps. Stud Ethnogr Ups. 1964:21:169-81.

Lagercrantz S. Spring-pole snares and their mechanisms. Stud Ethnogr Ups. 1966;26:15-133.

Lagercrantz S. Über afrikanische und südeuropäische Steindeckelfallen. Baessler Arch N S. 1972;20:239-60.

Lagercrantz S. Some ethnographic comments on Leonard Mascall's “A Booke of Engines" (1590). Stud Ethnogr Ups. 1984;40:1118.

Lagercrantz S. The Jesuit priest Heinrich Schacht and his mousetraps. In: Varia III (occasional papers XII), Uppsala; 1987. p. 20-29.

Leibold J. Improvement in animal-traps. Patent no. 219,959. United States Patent Office; 1879.

Lewthwaite GW. Improvement in animal-traps. Patent no. 221,329. United States Patent Office; 1879.

Marshall-Pescini S, Whiten A. Chimpanzees (Pan troglodytes) and the question of cumulative culture: an experimental approach. Anim Cogn. 2008;11:449-59.

Mascall L. A booke of engines and traps to take polecats, buzardes, rattes, mice and all other kindes of vermine and beasts whatsoeuer. In: Mascall L, editor. A booke of fishing with hooke \& line. Another of sundrie engines and trappes. London, pp. 51-93. Early English Books Online, accessed on: 22 Apr 2009; 1590

Mast JM (1899/1903) Patent No. 744,379. Animal-trap. United States Patent Office.

Maxim HS. My life. London: Methuen \& Co; 1915.

Mesoudi A. Foresight in cultural evolution. Biol Philos. 2008;23:243-55.

Mesoudi A, Whiten A, Laland KN. Is human cultural evolution Darwinian? Evidence reviewed from the perspective of The Origin of Species. Evolution. 2004;58:1-11.

Moore JH. Putting anthropology back together again: the ethnocentric critique of cladistic theory. Amer Anthropologist. 1994;96:925-48.

Nelson RR. Universal Darwinism and evolutionary social science. Biol Philos. 2007;22:73-94.

Nickel H. The mousetraps of the Mérode altar-piece again. Burlington Mag. 1966;108:577-80.

O’Brien MJ, Lyman RL. Evolutionary archeology: current status and future prospects. Evol Anthropol. 2004;11:26-36.

O'Brien MJ, Darwent J, Lyman RL. Cladistics is useful for reconstructing archaeological phylogenies: palaeoindian points from the Southeastern United States. J Archaeol Sci. 2001;18:1115-36.

O’Brien MJ, Lyman RL, Mesoudi A, VanPool TL. Cultural traits as units of analysis. Phil Trans R Soc B. 2010;365:3797-806.

Piggot (1898) Animal-trap. Patent no. 613,304. United States Patent Office.

Rice TG (1879) Improvement in animal-trap. Patent no. 215,480. United States Patent Office.

Richardson G (1874) Improvement in animal-traps. Patent no. 157,973. United States Patent Office.

Richerson PJ, Boyd R. Not by genes alone: how culture transformed human evolution. Chicago: Univ, Chicago Press; 2005.

Roth C. Medieval illustrations of mouse-traps. Bodleian Libr Rec. 1956;5:244-51. 
Ruhlen M. A guide to the world's languages. Stanford: Stanfor Univ Press; 1991.

Schäfer. Ägyptischer Vogelfang. Amtliche Berichte aus den Preußischen Kunstsammlungen. 1918/19;40(8):163-84.

Scott NE. An Egyptian bird trap. Metrop Mus Art Bull. 1940;35:163-4.

Shanks N, Joplin K. Of mousetraps and men: Behe on biochemistry. Rep NCSE. 2000;20(1-2):25-30.

Shapiro M. The Mérode mousetrap. Burlington Mag. 1966;108:430.

Tanner M (1694) Societas Jesu apostolorum imitatrix, sive gesta praeclara et virtutes eorum. Typis Universitatis Carolo-Ferdinandeae, in Collegio Societatis Jesu ad S. Clementem, per Adalbertum Georgium Konias, factorem, Pragae, pp. 794-796

Tëmkin I, Eldredge N. Phylogenetics and material culture. Curr Anthropol. 2007;48:146-53.
Tinker H (1882) Animal-trap. Patent No. 265,892. United States Patent Office

Troumble CB (1892) Animal-trap. Patent no. 481,707. United States Patent Office

Web Gallery of Art (2010) Mérode Altarpiece by the Master of Flémalle. Available at: http://www.wga.hu/tours/flemish/flemalle/ index.html. Accessed on: 25 Nov 2010.

Wells GH (1892) Animal-trap. Patent no. 469,429. United States Patent Office.

Wimsatt WC. Genes, memes and cultural history. Biol Philos. 1999;14:279-310.

Wright Wm (1860) Animal-trap. Patent no. 28,820. United States Patent Office.

Zupnick IL. The mystery of the Mérode mousetrap. Burlington Mag. 1966;108:126-33. 